\title{
Delayed settling of marine snow: effects of density gradient and particle properties and implications for carbon cycling
}

\author{
Jennifer C. Prairie ${ }^{\text {a b* }}$, Kai Ziervogel ${ }^{\text {a }}$, Roberto Camassa ${ }^{\text {b }}$, Richard M. McLaughlin ${ }^{\text {b }}$, Brian L. \\ White $^{\mathrm{a}}$, Carolin Dewald ${ }^{\mathrm{c}}$, and Carol Arnosti ${ }^{\mathrm{a}}$ \\ * Corresponding author: jcprairie@sandiego.edu \\ Permanent address: University of San Diego \\ Department of Environmental and Ocean Sciences \\ 5998 Alcalá Park \\ San Diego, CA 92110-2492
}

Phone: (619) 260-8820

\footnotetext{
a Department of Marine Sciences, University of North Carolina at Chapel Hill, Chapel Hill, North Carolina 27599 USA

b Carolina Center for Interdisciplinary Applied Mathematics, Department of Mathematics, University of North Carolina at Chapel Hill, Chapel Hill, North Carolina 27599 USA

c Friedrich Schiller University Jena, Otto Schott Institute of Materials Research, Löbdergraben 32

D-07743 Jena, Germany
} 


\section{$\underline{\text { Abstract }}$}

Marine snow aggregates are often a dominant component of carbon flux and are sites of high bacterial activity; thus, small-scale changes in the settling behavior of marine snow can affect the vertical locations of carbon export and remineralization in the surface ocean. In this study, we experimentally investigated the sinking velocities of marine snow aggregates formed in roller tanks as they settled through sharp density gradients. We observed between 8 and 10 aggregates in 3 different experiments, each of which displayed delayed settling behavior - that is, a settling velocity minimum - as they crossed the density transitions. Characteristics of delayed settling behavior were also compared to density stratification and aggregate density and size; aggregate settling velocity decreased more, and for longer periods of time, when density gradients were sharper and when aggregates were less dense. The observed relationships between non-dimensional parameters and aggregate settling allow for direct application of our results to the field, providing insight into the conditions under which strong delayed settling behavior is likely to occur. Activities of extracellular enzymes (the initial step in microbial remineralization of organic matter) were more than an order of magnitude higher in the aggregates compared to the surrounding water from which the aggregates were derived. Coupling measured enzyme activities with observations of delayed settling behavior demonstrates that the extent as well as the vertical location of enzyme activity is strongly affected by aggregate settling behavior: total enzyme activity within the region of the density transition increased by a factor of 18 with increasing stratification. This study, which combines direct measurements of small-scale aggregate settling and microbial enzyme activity, offers an opportunity to determine the potential implications of delayed settling behavior for local and larger-scale carbon cycling in the ocean. 


\section{Introduction}

Marine snow plays an important role in the carbon cycle, as a primary component of carbon export from the surface ocean (Alldredge and Silver, 1988; Kiørboe, 2001), and as sites of high bacterial activity and carbon remineralization (Smith et al., 1992; Grossart et al., 2007; Ziervogel and Arnosti, 2008; Ziervogel et al., 2010). An understanding of marine snow settling behavior is thus essential to determining controls on the efficiency of the biological pump, that is, the balance between carbon flux and remineralization in various parts of the world's oceans (De La Rocha and Passow, 2007).

Much of the research on the role of marine snow aggregates in carbon export considers average sinking rates or flux over the length of the water column (Turner, 2002; Guidi et al., 2009). In many cases, however, aggregate settling rates may change dramatically on much smaller scales (McDonnell and Buesseler, 2010). In particular, aggregates may decrease settling velocity when passing through sharp density gradients (Derenbach et al., 1979; Alldredge and Crocker, 1995; MacIntyre et al., 1995; Alldredge et al., 2002; Kindler et al., 2010). This behavior has been proposed as a possible mechanism for the formation of aggregate thin layers at density discontinuities. This delayed settling behavior across sharp density gradients can occur by two mechanisms. First, aggregates can entrain lighter fluid downward as they enter the denser fluid, thus temporarily decreasing the aggregate's settling velocity. This entrainment mechanism has been studied both experimentally and theoretically for solid spheres (Srdić-Mitrović et al., 1999; Abaid et al., 2004; Camassa et al., 2009, 2010). In addition, since marine snow is extremely porous, its density can change depending on the density of the surrounding fluid. Thus, at times aggregates may be initially too light to settle through a density discontinuity, but after denser fluid has diffused into the aggregate, it can continue to sink. This mechanism of delayed settling 
has been termed diffusion-limited retention, and has been studied theoretically and experimentally for porous spheres (Kindler et al., 2010; Camassa et al., 2013). In a recent study, both entrainment and diffusion-limited retention have been observed in the laboratory to cause delayed settling in marine aggregates (Prairie et al., 2013). Prairie et al. (2013) found that every aggregate in their study displayed a settling velocity minimum when passing through the sharp density transition, demonstrating that delayed settling behavior is relevant to natural marine aggregates, at least in a laboratory setting.

To determine the manner in which the strength of the density gradient and aggregate properties may mediate delayed settling behavior, we conducted a series of experiments with marine snow aggregates formed in roller tanks from coastal seawater. These aggregates were observed as they settled through stratified water columns to investigate the manner in which settling behavior was affected by changes in the strength of the density gradient, aggregate density, and aggregate size. Concurrently, we measured rates of microbial enzyme activities on the aggregates and in the surrounding seawater from which they were derived. The activities of extracellular enzymes initiate microbial remineralization of organic matter (Arnosti, 2011). By coupling aggregate settling behavior with rates of enzymatic hydrolysis, we investigated the consequences of the observed delayed settling behavior for the locations and extent of organic matter remineralization in the water column.

\section{Methods}

In three sets of experiments, marine snow aggregates of various sizes and densities were formed in roller table incubations of coastal seawater (Table 1). Each aggregate was individually tracked as it settled in three stratified tanks with progressively sharper density gradients. Delayed 
settling behavior was related to changes in density gradient strength, aggregate density, and aggregate size. We also explored the consequences of changes in aggregate settling behavior for microbial activity in the water column through concurrent measurements of microbial enzyme activity in the aggregates and in the surrounding seawater following aggregate formation.

\section{1. Formation of Aggregates}

Seawater was collected from Bogue Sound, North Carolina (NC) for Experiments 1 and 2 and from the Outer Banks, NC for Experiment 3 (Table 1), and was stored at $4{ }^{\circ} \mathrm{C}$ in the dark until use (no longer than 15 days after collection). Aggregates were formed by filling seawater into acrylic cylindrical tanks (total volume $~ 5 \mathrm{~L}$ ) that were incubated on a roller table, an approach that is widely used to study marine snow in the lab (Shanks and Edmondson, 1989; Jackson, 1994; Ziervogel and Forster, 2005; Ploug et al., 2008; Ziervogel and Arnosti, 2008; Ziervogel et al., 2010). The tanks were incubated for ca. 48 hours at a rotation speed of approximately $2.5 \mathrm{rpm}$ at room temperature $\left(\sim 21^{\circ} \mathrm{C}\right)$ in both light and darkness. After this initial period, 300 to $700 \mathrm{~mL}$ of a mixed culture of senescent diatoms (containing aliquots of Fragilariopsis sp., Thalassiosira sp., Pseudo-nitzschia sp., Chaetoceros sp., Cylindrotheca sp., Skeletonema sp., Phaeodactylum sp.) were added to the tanks; subsequently the tanks were incubated on the roller table for an additional day under the same conditions as described above. The addition of diatom culture and time of incubation was chosen to form aggregates that were sufficiently robust for the settling experiments (see below). At the end of the incubation, roller tanks were placed on their sides on the bench and single aggregates that settled to the bottom of the tank were individually removed from the tank water using volumetric pipettes with cut-off tips. For each experiment, 15-20 aggregates were collected to observe settling behavior 
individually in the stratified tanks. An additional 30-45 aggregates were collected to measure porosity of the aggregate batch (see section 2.6); 18-45 aggregates were also collected for enzyme activity measurements (see section 2.7). Note that after seawater was collected, the microbial community was likely to change substantially during storage prior to aggregate formation; thus, the enzyme activity measurements are not intended to reflect those of the in situ community.

\subsection{Measuring Aggregate Size}

All aggregates collected (for the stratified settling tanks, for porosity measurements, and for enzyme activity measurements) were sized by microscopy. Individual aggregates were placed on top of a millimeter square grid in a petri dish containing water from the tank in which they were formed. Aggregates were then photographed with a digital microscope (Model 26700-300, Aven Inc.), producing images of the two-dimensional projection of the aggregate (Fig. 1). Images were processed using MATLAB to determine the cross-sectional area, which was used to calculate the equivalent spherical diameter (ESD) for each aggregate, i.e. the cross sectional area was assumed to represent that of a sphere with an equivalent cross-sectional area. Since the aggregates are irregularly shaped and are most likely to lie such that their largest cross-section is the area imaged, the estimates of equivalent spherical diameter for each aggregate are approximate and likely overestimated.

\subsection{Calculating Aggregate Densities}

Aggregate densities were calculated for each of the aggregates to be observed for settling behavior in the stratified tanks. The settling velocities of these aggregates were first measured in 
water of homogenous density approximately equal to that of the source water in which they were formed (see Table 1). After measuring their sizes as described above, individual aggregates were gently transferred by pipette with a cut-off tip to a rectangular tank with a base $18 \times 18 \mathrm{~cm}$ and a height of $32 \mathrm{~cm}$. The path of the aggregate as it settled in the tank was recorded using a Pike F100B camera (Allied Vision Technologies, Germany) recording at a rate between 12 and 25 frames $\mathrm{s}^{-1}$ (the rate remained constant within an experiment). Sinking velocity was calculated from the vertical displacement (captured at the recording rate of the camera) and then an average sinking velocity $(U)$ was calculated over at least 3 continuous seconds. This was used to estimate aggregate density $\left(\rho_{a}\right)$ using the following equation (Batchelor, 1967; Ploug et al., 2008):

$$
U=\sqrt{\frac{4 g\left(\rho_{a}-\rho_{f}\right) d}{3 \rho_{f} C_{D}}}
$$

where $g$ is the acceleration due to gravity, $\rho_{f}$ is the density of the fluid, $C_{D}$ is the drag coefficient, and $d$ is the equivalent spherical diameter as measured from the microscope images. The drag coefficient was calculated using the following empirical drag law (White, 1974):

$$
C_{D}=\frac{24}{R e}+\frac{6}{1+R e^{0.5}}+0.4
$$

for $\operatorname{Re}>0.5$ where Re is the Reynolds number calculated as:

$$
R e=\frac{d U}{v}
$$

where $v$ is the kinematic viscosity of water $\left(1.05 \times 10^{-2} \mathrm{~cm}^{2} \mathrm{~s}^{-1}\right.$ at $\left.20^{\circ} \mathrm{C}\right)$. Since the above equations assume spherical particles, the calculated density is approximate for each aggregate. Since aggregates are porous, their densities also depend on the fluid in which they are measured; the aggregate densities reported here are estimated in the water used for the top layer of the stratified experiments, approximately equal to the density of the ambient water in which they 
were originally formed (see Table 1). Equivalent spherical diameter and density for each of the aggregates observed in all three stratified tanks for each experiment are shown in Table 2.

\subsection{Two-Layer Aggregate Settling Experiments}

After aggregate densities were calculated, the aggregates were observed as they settled through three 2-layer water columns with increasingly sharp density transitions in the middle (referred to as Tank 1, Tank 2, and Tank 3). The three identical tanks used in these experiments had a square base $(20 \mathrm{~cm} \times 20 \mathrm{~cm})$ and a height of $60 \mathrm{~cm}$ (Fig. 2). Prior to the experiments, the tanks were filled to a height of approximately $30 \mathrm{~cm}$ with artificial salt water (hereafter referred to as bottom layer fluid) that was denser than the water in which the aggregates were formed; the density of the bottom layer fluid increased from Tank 1 to Tank 3 (Table 1). All water densities were measured using a DMA 35 Portable Density Meter (Anton Paar, Austria). After the bottom layer fluid was still, water with density approximately equal to that of the water in which the aggregates were formed - defined as the top layer fluid - was carefully poured on top of the bottom layer fluid through a diffuser initially soaked with top layer fluid. The diffuser floats at the surface of the water column; it is $\sim 2 \mathrm{~cm}$ thick and is constructed of foam and sponge to slow down the flow of top layer fluid as it is introduced into the tank in order to create a sharp density transition between the top layer and bottom layer fluid (Abaid et al., 2004; Camassa et al., 2009). The same top layer fluid was used for all three tanks in each experiment, such that the density gradient became sharper from Tank 1 to Tank 3 (Fig. 2).

Aggregates were gently transferred individually by pipette into Tank 1 to observe their settling behavior. After settling through the density gradient, each aggregate landed in a square grid container that was placed at the bottom of Tank 1 and Tank 2 before top layer fluid was 
added. These square grid containers consisted of $1 \mathrm{~cm} \mathrm{x} 1 \mathrm{~cm}$ square holes arranged in a 7 by 13 square grid. This container allowed for collection and retrieval of each individual aggregate, so that the settling behavior of the same aggregates could be observed in the subsequent tanks. The location of each aggregate in the square grid was recorded to allow for settling behavior to be compared for an individual aggregate among all three tanks. Aggregates that visibly broke into pieces, landed outside the container, or landed inside a hole with another aggregate were discarded and their settling behavior was not analyzed. After all aggregates were observed in Tank 1, a lid was placed on top of the grid container and it was carefully removed from the tank. Each of the aggregates was placed in an individual vial to soak in top layer fluid for at least 45 minutes before being observed in Tank 2. Aggregates were observed and retrieved in Tank 2 in the same way, and again soaked in top layer fluid for at least 45 minutes before being observed in Tank 3. Only aggregates that were successfully observed in all three tanks were analyzed (between 8 and 10 per experiment; see Table 1).

The soaking time of aggregates in top layer fluid between each tank was chosen to be theoretically long enough for the settling behavior of the aggregate in the top layer of each tank to be equivalent. However, boundary layer effects in some of the aggregates may have resulted in some excess salt being retained before each new tank run, thus affecting settling behavior.

For all three tanks, aggregate settling behavior was recorded using the Pike camera, recording at a frame rate that was constant within runs, but varied between 12 and 32 frames s ${ }^{-1}$ among runs. Recordings were conducted with the room dark and the tank lit from the sides, using light-emitting diode (LED) strips attached to two panels that spanned the height and width of the tank. Although the LED panels introduced some heat laterally into the tank, previous experiments indicate that the rise in temperature is slight $\left(<1^{\circ} \mathrm{C}\right.$ over the course of an 
experiment) and any convective motion was negligible in comparison to aggregate settling velocities (Prairie et al., 2013). The square field of view of the images had dimensions which ranged among experiments between $\sim 30.5 \mathrm{~cm} \mathrm{x} 30.5 \mathrm{~cm}$ and $32 \mathrm{~cm} \mathrm{x} 32 \mathrm{~cm}$. The top of the field of view was positioned $\sim 21-24 \mathrm{~cm}$ below the surface (varied between experiments, but kept constant for each tank). The size of the field of view was chosen to maximize the vertical distance that the aggregate could be tracked while retaining adequate resolution of the aggregate.

The density gradient was measured in each tank by profiling with a conductivity and temperature probe (MSCTI Model 125, Precision Measurement Engineering, Inc., USA) after all the aggregates were observed in that tank, but before the grid container was removed. Measurements were taken vertically every 1-3 cm using a mm-precision linear slide (Velmex Inc., USA) to which the conductivity and temperature probe was attached. Density was calculated from conductivity and temperature using the Gibbs-SeaWater Oceanographic Toolbox (McDougall and Barker, 2011), and then linearly corrected to match the top and bottom layer measured densities. The density and depth data for each tank were then fitted to a hyperbolic tangent function of the form:

$$
\rho=\left(\frac{\rho_{B L}-\rho_{T L}}{2}\right)\left(1+\tanh \left(\frac{z-z_{0}}{z_{t h}}\right)\right)+\rho_{T L}
$$

where $\rho$ is density, $z$ is depth, $\rho_{T L}$ and $\rho_{B L}$ are the density of the top layer and bottom layer fluid respectively, and the parameters $z_{0}$ (mid-depth) and $z_{t h}$ (density transition thickness) were adjusted to result in the best fit to the data. Density profiles from all tanks resulted in a fit with $\mathrm{r}^{2}$ $>0.99$.

Buoyancy frequency, $N$, was calculated from this hyperbolic tangent fit density profile using:

$$
N=\sqrt{-\frac{g}{\rho} \frac{\Delta \rho}{\Delta z}}
$$


where $g$ is the acceleration due to gravity (Table 3).

\subsection{Settling Behavior Analysis}

All images from the Pike camera were processed in MATLAB to determine the location of the aggregate (defined as the location of its centroid) over time. Position data was linearly corrected from pixels to cms using the measured dimensions of the field of view of the camera. The settling velocity was calculated by dividing the aggregate's vertical displacement between sequential images by the time between images; the settling velocity was then smoothed using a moving average over approximately a 1 second span.

Two metrics were calculated to determine the extent to which the aggregate's settling velocity decreased within the density transition, as described in Prairie et al. (2013). The normalized minimum settling velocity (NMSV) was calculated as the minimum value of the smoothed settling velocity (MSV) divided by the settling velocity in the bottom layer. The settling velocity in the bottom layer was calculated by averaging the smoothed settling velocity in the very last part of the settling velocity time record (for a period of at least $1.5 \mathrm{~s}$ ), representing the point at which the aggregate had reached its terminal velocity after passing through the density transition. The delayed settling time (DST) was calculated as the length of time that the aggregate's smoothed settling velocity was less than $90 \%$ of the settling velocity in the bottom layer. This definition for delayed settling time was chosen because it quantified the time of delayed settling of the aggregate independent of its settling velocity; the threshold of $90 \%$ was chosen to obtain a positive time scale even for aggregates that decreased their velocity only slightly, while limiting the effect of noise. This metric was then non-dimensionalized, defining the delayed settling time scale (DSTS) as: 


$$
\mathrm{DSTS}=\frac{(\mathrm{DST})\left(u_{T L}\right)}{z_{t h}}
$$

where $u_{T L}$ is the settling velocity of the aggregate in the top layer and $z_{t h}$ is the density transition thickness as obtained from eq. (4). By normalizing in this way, DST is effectively being divided by the length of time the aggregate would take to settle through the same distance if no density gradient were present. Thus, since DST measures the length of time the aggregate slowed down, DSTS represents the enhancement of settling time due to delayed settling (such that a DSTS value of 1 represents a doubling in total settling time when compared to no delayed settling behavior).

NMSV and DSTS were calculated individually for each aggregate and each tank and compared to density gradient and aggregate properties. For comparison with delayed settling behavior, aggregate density and aggregate size were also non-dimensionalized. Normalized excess aggregate density, $\overline{\Delta \rho}$, was defined as

$$
\overline{\Delta \rho}=\frac{\rho_{a}-\rho_{T L}}{\rho_{B L}-\rho_{T L}}
$$

Note that a value of normalized excess aggregate density less than 1 implies that the initial aggregate density in the top layer fluid $\left(\rho_{a}\right)$ is less than the density of the bottom layer fluid $\left(\rho_{B L}\right)$. Normalized aggregate size, $\overline{\mathrm{ESD}}$, was calculated from the measured equivalent spherical diameter (ESD) of each aggregate as:

$$
\overline{\mathrm{ESD}}=\frac{\mathrm{ESD}}{z_{t h}}
$$

\subsection{Measuring Aggregate Porosity}

For each experiment, the dry mass of three sets of 10 or 15 aggregates each were measured by filtering onto pre-weighed and pre-combusted GF/F filters under low vacuum. For 
each set of aggregates, the collective dry mass $(W)$ and volume $(V)$ (obtained by summing the individual aggregate volumes approximated from the microscope images) were used to calculate the solid matter density $\left(\rho_{s}\right)$ using the equation given in Ploug et al. (2008):

$$
\rho_{a}-\rho_{f}=\frac{W}{V} \times\left(1-\frac{\rho_{f}}{\rho_{s}}\right)
$$

where the mean aggregate density was used for $\rho_{a}$ and the density of the top layer fluid was used for $\rho_{f}$. Porosity $(P)$ was then calculated using:

$$
P=1-\frac{W / \rho_{s}}{V}
$$

The porosity for each set of aggregates measured was then averaged and is shown for each experiment in Table 1.

\subsection{Measurements of Microbial Enzymatic Activity}

For each of the three experiments, microbial extracellular enzymatic activities were measured in aggregates (AGG) and surrounding tank water in which the aggregates were formed (SW) according to Hoppe (1983). We used L-leucine-4-methylcoumarinyl-7-amide (MCA) hydrochloride, MUF- $\beta$-D-glucopyranoside, and MUF- $\alpha$-D-glucopyranoside (all substrates from Sigma-Aldrich) as substrate proxies to measure leucine-aminopeptidase (hereafter referred to as peptidase), $\beta$-glucosidase, and $\alpha$-glucosidase activities, respectively. After measuring aggregate sizes (see Section 2.2), individual aggregates were incubated in disposable acrylic cuvettes that had autoclaved seawater and substrate proxies at enzyme-saturating levels (400 $\mu \mathrm{M}$ final substrate concentration). Experiment 1 and 3 had 5 aggregates in triplicate cuvettes; enzyme activities in Experiment 2 were measured in duplicate vials with $n=3$ aggregates. The same numbers of cuvettes were prepared with SW that had no visible aggregates. Incubations were conducted at room temperature in the dark. Changes in fluorescence over time were monitored 3 
times over an incubation time of 3-4 hours using a Turner Biosystems TBS-380 fluorometer, with excitation/emission channels set to "UV” (365 nm excitation, 440-470 nm emission). Control incubations were made with autoclaved seawater; these incubations showed no significant changes in fluorescence over time. Fluorescence changes in the live treatments were converted to molar units using MUF and MCA standard solution.

\section{$\underline{\text { 3. Results }}$}

A settling velocity minimum was observed for every aggregate in all three stratified tanks for each experiment. However, the extent of delayed settling behavior (as measured by the normalized minimum settling velocity, NMSV, and delayed settling time scale, DSTS) varied considerably among the aggregates even within an experiment and for the same density gradient (Table 4). NMSV ranged from less than 0 (indicating the aggregate came to a full stop) to 0.72. The few slightly negative NMSV values observed here are within video recording noise, although we note that in some cases in previous studies (e.g., Abaid et al. 2004 and Lin 2009 for solid particles; Prairie et al. 2013 for aggregates), particles have been observed to temporarily reverse direction at sharp density gradients. DSTS also displayed a large range among aggregates, spanning almost two orders of magnitude from 4.4 to 271.7. This variation in NMSV and DSTS can be attributed to the significant differences in size, shape, and density of the aggregates (Figure 1; Table 2).

Despite this variation, when considering all aggregate data collectively, DSTS was significantly different between each pair of tanks, with larger DSTS being associated with tanks with sharper density gradients ( $\mathrm{p}<0.05$ using two-sample t-test). NMSV was found to be 
significantly lower for tanks with sharper density gradients, except no difference was found between Tank 2 and Tank 3.

When comparing the change in NMSV or DSTS from tank to tank for each individual aggregate, an even clearer pattern emerges. This change in settling behavior from Tank 1 to Tank 3 - decreasing NMSV and increasing DSTS - is shown for one of the aggregates in Figs. 3 and 4. NMSV decreased for all 27 aggregates from Tank 1 to Tank 2 and decreased for 21 of the 27 aggregates from Tank 2 to Tank 3 (where density gradient increased in sharpness from Tank 1 to Tank 3; Fig. 5A, B). For all but 2 of the aggregates that showed an increase in NMSV from Tank 2 to Tank 3, the aggregates already displayed an NMSV of $\leq 0$, indicating they came to a full stop at the density gradient. Similarly, DSTS increased for all 27 aggregates from Tank 1 to Tank 2 and increased for all but two of the aggregates from Tank 2 to Tank 3 (Fig. 5C, D). These results suggest that as density gradients become sharper, the delayed settling behavior becomes more pronounced, with aggregates slowing down to a greater extent (smaller NMSV) and for a longer time (larger DSTS).

Aggregate delayed settling behavior was also associated with normalized excess aggregate density, $\overline{\Delta \rho}$ (Fig. 6). NMSV was positively correlated with $\overline{\Delta \rho}(\mathrm{p}<0.001)$, although the relationship is clearly not linear given that NMSV has an upper bound of 1 (Fig. 6A). Likewise, DSTS was negatively correlated with $\overline{\Delta \rho}$ (Fig. 6B; $\mathrm{p}<0.001$ ). Considering data from all three experiments collectively, the relationship between DSTS and $\overline{\Delta \rho}$ is explained well by a fit of the form $y=a x^{-1}$ with fit parameter value $a=29.2\left(\mathrm{r}^{2}=0.56\right)$ (Fig. 6B). These observed trends suggest that a higher excess aggregate density will result in a smaller decrease in settling velocity when passing through a sharp density gradient, and with the slow down occurring for a shorter period of time. 
Relationships were also observed between delayed setting behavior and aggregate size. Fitting the data using linear least squares, NMSV was found to be significantly negatively correlated with $\overline{\operatorname{ESD}}(p=0.017)$, although the fit was quite weak $\left(r^{2}=0.070\right.$; Fig. 7A) with parameters of the linear fit $y=a x+b$ (95\% confidence intervals in brackets) $a=-0.76$ [-1.38, $0.14]$ and $b=0.33[0.20,0.46]$. DSTS was positively correlated with $\overline{\operatorname{ESD}}(\mathrm{p}<0.001)$, with a stronger fit $\left(r^{2}=0.264\right.$; Fig. 7B), with parameters of the linear fit (95\% confidence intervals in brackets) $a=452[283,620]$ and $b=-24.9[-59.4,9.7]$.

Measurements of microbial enzymatic activity taken during each experiment show that enzymatic activity on the aggregates (AGG) was greatly enhanced relative to the surrounding tank water (SW). In all three experiments and for all three substrates tested, leucine aminopeptidase activity was close to two orders of magnitude higher in the aggregates than in the surrounding water from which the aggregates were formed. Beta- and alpha-glucosidase activities were considerably lower than leucine aminopeptidase activities, but were also one to two orders of magnitude higher in the aggregates than in the surrounding water (Table 5).

Averaging the enzyme activities for the three experiments (Table 5) yields a total enzyme activity of ca. 3.18 pmol monomer $\mathrm{ml}^{-1}$ aggregate $\mathrm{s}^{-1}$. This summed enzyme activity was coupled with the settling behavior of aggregates to determine the extent that delayed settling behavior can enhance hydrolytic activity around the density interface. We note that this calculation assumes that enzymatic activities are constant for suspended and for sinking aggregates, although microbial cells may react differently when attached to sinking vs suspended aggregates. For all three tanks, we calculated a "residence time" of the aggregates in the region of the density interface (chosen as a vertical span of $12 \mathrm{~cm}$ since this contained the entire region in which the aggregate's settling velocity was decreased). For the unstratified tank, a similar residence time 
was obtained by dividing the same vertical span by the aggregate's average settling velocity in the absence of a density gradient. Given this, the enzyme activity could be calculated for the time that the aggregate was in this $12 \mathrm{~cm}$ region around the density interface. For example, for Aggregate 10 in Experiment 2 (shown in Figs. 3 and 4), the enzyme activity in the region of the density interface would be 44, 85, 443, and 805 pmol monomer $\mathrm{ml}^{-1}$ aggregate for the unstratified tank, Tank 1, Tank 2, and Tank 3, respectively. This represents an increase in enzyme activity at the density interface over the unstratified tank by a factor of 1.9 for Tank 1, 10.1 for Tank 2, and 18.4 for Tank 3. As a rough approximation, assuming a dissolved organic carbon (DOC) concentration of $80 \mu \mathrm{M}$ at the density interface, which is equivalent to ca. 13 $\mu \mathrm{mol}$ of a six-carbon compound (and assuming the DOC was amenable to hydrolysis by these enzymes), an aggregate could hydrolyze 0.7\% (Tank 1), 3.4\% (Tank 2), and 6.2\% (Tank 3) of total DOC in this area around the density interface under these conditions. In the unstratified tank, by comparison only $0.3 \%$ of DOC would be hydrolyzed at the same depth interval by the same aggregate. These calculations indicate that the potential for enzyme activity in the region of the density interface was greatly enhanced with increasing stratification (Fig. 8).

\section{Discussion}

\subsection{Trends and mechanisms for delayed settling}

Our observations of marine snow settling across sharp density gradients help elucidate the manner in which density stratification and aggregate density and size affect delayed settling behavior, an important step to understanding this phenomenon in natural conditions and in a larger context. The results support previous studies showing that aggregates may decrease their 
settling velocity when passing through a density transition (Kindler et al. 2010; Camassa et al., 2013; Prairie et al., 2013). The present study further examines the relationship between stratification and delayed settling behavior; individual aggregates were compared across multiple density gradients to isolate the effect of density gradient from the natural variation in aggregate size, shape, and composition. One source of error in comparing individual aggregate settling behavior across the three tanks is the potential retention of some excess salt in aggregates because of an insufficient soaking time in top layer fluid between tanks. However, if an aggregate retained excess salt (and thus had a higher initial aggregate density than the previous tank), the effects on observed delayed settling behavior would be lower DSTS and higher NMSV. This means that considering this source of error, the observed trends of increasing DSTS and decreasing NMSV with increasing density stratification would still hold; moreover, the actual potential increases in DSTS and decreases in NMSV between tanks could be more extreme than observed in our experiments.

The most striking predictor of delayed settling behavior was normalized excess aggregate density, $\overline{\Delta \rho}$. NMSV was positively correlated with $\overline{\Delta \rho}$ and DSTS was negatively correlated with $\overline{\Delta \rho}$ (Fig. 6), indicating that, all other factors held constant, relatively denser aggregates will not decrease their settling velocity as dramatically when passing through density transitions. This trend is intuitive, but the observed relationships, particularly the power-law relationship between DSTS and $\overline{\Delta \rho}$, are important for predicting the nature of delayed settling behavior in the field.

This non-dimensional number, $\overline{\Delta \rho}$, is also useful as it provides insight into the underlying mechanism of the observed delayed settling behavior. As defined in eq. (7), for an aggregate settling through a sharp density gradient, $\overline{\Delta \rho}$ represents the extent to which the aggregate's density exceeds that of its surrounding top layer fluid relative to the density difference of the 
upcoming density transition. Assuming that the aggregate is always initially denser than the top layer fluid, $\overline{\Delta \rho}$ is always positive. However, an important regime shift occurs at $\overline{\Delta \rho}=1$ : a value less than 1 indicates the aggregate is initially lighter than the density of the bottom layer fluid. In this regime, any delayed settling behavior must be at least partially controlled by diffusionlimited retention, since denser fluid must diffuse into the aggregate for it to have the chance to continue to settle (Prairie et al., 2013). By contrast, when $\overline{\Delta \rho}>1$, the aggregate is initially denser than the bottom layer fluid, and so, although diffusion will still occur, no diffusion is necessary for the aggregate to continue to settle and the dominant mechanism for delayed settling is entrainment of lighter fluid (Prairie et al., 2013). We may expect to be able to verify that diffusion-limited retention is the dominant mechanism in the regime where $\overline{\Delta \rho}>1$ based on the relationship of DSTS and aggregate size; theory predicts that delayed settling time should be a function of particle radius squared (Kindler et al. 2010; Prairie et al. 2013). However, we do not see this expected relationship; this outcome can potentially be explained by the extremely nonspherical shapes of the aggregates (see below for full discussion of aggregate size and shape) and the fact that entrainment also plays a role in diffusion-limited retention (Camassa et al. 2013). Although both mechanisms of delayed settling interact with one another and the fluid dynamics behind delayed settling can be quite complex (Camassa et al., 2013), these regimes provide a first-order way of identifying the potential dominant mechanism.

As with Prairie et al. (2013), both regimes were observed in this study, as indicated by the $\overline{\Delta \rho}$ values for each aggregate in each tank in Table 2. In fact, several aggregates switched regimes from entrainment dominated to diffusion-limited retention dominated as they moved from Tank 1 to Tank 3 . The shift from the entrainment regime to the diffusion-limited retention regime usually accompanied a decrease in NMSV to near 0 and a large increase in DSTS, 
consistent with the observations of Prairie et al. (2013). These delayed settling regimes also highlight marked differences between the three experiments: in Experiment $1 \overline{\Delta \rho}<1$ for all three tanks for most aggregates, while $\overline{\Delta \rho}$ remained greater than 1 for all aggregates in Experiment 3. In Experiment 2, a mix of the two regimes was observed. It is interesting to note that, despite the fact that aggregate setting behavior in these two regimes may be controlled by very different mechanisms, no difference was observed in the relationship between DSTS and $\overline{\Delta \rho}$ for the two regimes, as can be seen to the left and to the right of the dashed black line in Fig. 6C. That is, no significant change in the slope of the power-law relationship was found when fitting the data separately for the two regimes, although some caution should be taken as there is a significant amount of spread in the data.

Although delayed settling behavior was also associated with normalized aggregate size, $\overline{\mathrm{ESD}}$, the observed relationships were much weaker than those observed vs. normalized excess aggregate density, $\overline{\Delta \rho}$ (Fig. 7). Prairie et al. (2013) proposed that the relationship between delayed settling behavior and aggregate size will depend on the mechanism for delayed settling; DST should increase with aggregate size for diffusion-limited retention but decrease with aggregate size when entrainment is the dominant mechanism. However, fitting the data separately for the two regimes resulted in weaker fits and clearly differing patterns did not emerge (Fig. 7). The trends that were observed for all the data collectively indicate that increasing aggregate size leads to lower NMSV and higher DSTS following the predictions of Prairie et al. (2013) for the diffusion-limited retention regime; this may be expected since aggregates in this regime have more extreme values of DSTS which would skew the overall data patterns. One potential explanation for the large scatter in the delayed settling behavior data vs. aggregate size is the effects of aggregate shape and composition (which varied significantly even 
within an experiment; Fig. 1). Although the manner in which aggregate shape specifically affects delayed settling behavior has not yet been investigated, previous research has indicated that the irregular shapes of aggregates do affect their settling velocity, since aggregate settling velocity is lower than equivalently sized spherical particles (Alldredge and Gotschalk 1988). Moreover, since aggregates have been shown to be fractal, we would not necessarily expect a regular scaling between aggregate settling properties and size (Logan and Wilkinson 1990; Kilps et al. 1994); this point may also explain the power-law relationship observed between $\overline{\Delta \rho}$ and delayed settling properties. Another factor to consider is the error associated with using the metric of equivalent spherical diameter as a proxy for aggregate size for aggregates that are very irregularly shaped. However, other metrics that were tried (such as maximum length) produced similar results.

\subsection{Implications of results for natural field conditions}

The results presented in this study demonstrate the effects of density gradient, aggregate density, and aggregate size on delayed settling behavior of marine aggregates in a laboratory setting. Although many of the conditions in our experiments are different from those in the natural marine environment, our results provide insight into the manner in which aggregate settling may be affected by sharp density gradients in the field. In particular, by using nondimensional aggregate properties and metrics of delayed settling behavior, our results can be directly applied to situations with conditions quite different from those in our experiments.

The two most important differences between our experiments and natural conditions are the facts that (i) the density gradients in our experiments are extremely sharp compared to those in most coastal environments and (ii) the aggregates made in the laboratory used for the 
experiments are much denser than those formed in most coastal diatom blooms (Shanks, 2002). These two factors have opposite effects on aggregate delayed settling behavior; while the sharper density gradient results in higher DSTS, the higher density of the aggregates leads to decreased DSTS. To better understand the implications for delayed settling in natural coastal environments, we can estimate a reasonable value of normalized excess aggregate density, $\overline{\Delta \rho}$, from previous field studies on marine snow. Assuming other parameters are held constant, we should expect similar aggregate delayed settling behavior with equivalent values of this non-dimensional number, $\overline{\Delta \rho}$. In Alldredge et al. (2002), a thin layer of large marine aggregates was observed at $\sim 5 \mathrm{~m}$ depth associated with a sharp halocline that represented a density change of $\sim 0.001 \mathrm{~g} \mathrm{~cm}^{-3}$ over $\sim 2 \mathrm{~m}$ vertical distance. Since aggregate density was not measured in Alldredge et al. (2002), we used excess density $\left(\rho_{a}-\rho_{T L}\right)$ values of natural marine snow particles $\left(0.00019 \mathrm{~g} \mathrm{~cm}^{-3}\right.$ from Ploug et al., 1999 and Ploug et al., 2008), estimating a value of $\overline{\Delta \rho}=0.19$. This is a reasonable value for marine snow particles settling through sharp density gradients in some coastal regions; it would fall on the lower end of aggregates observed in our experiments and would fall in the diffusion-limited retention regime of delayed settling. The relationship observed between DSTS and $\overline{\Delta \rho}$ (Fig. 6C) would predict DSTS $>146$ in this scenario, indicating that the length of time for the aggregate to settle through the 2-meter density transition would be 147 times longer than if no density gradient were present. In dimensional terms, this means the aggregate would have a delayed settling time in the density transition of almost 3 days (using $u_{T L}=100 \mathrm{~m} \mathrm{day}^{-1}$ and $z_{t h}=2 \mathrm{~m}$; Alldredge et al., 2002), very similar to the upper range of residence times found by Kindler et al. (2010). Although factors not considered in this study (such as interaction effects between setting particles and turbulence, which can erode density gradients) may make this 3day delayed settling time unlikely, it is clear from this general analysis that the settling behavior 
and thus flux of aggregates in certain stratified coastal regions can be greatly affected by delayed settling through density interfaces. In fact, the aggregate thin layer observed in Alldredge et al. (2002) persisted for over 24 hours. The trends observed in this study suggest that delayed settling is likely to be most important in cases where lighter, fluffy aggregates are settling through sharp density gradients, for example in estuarine environments. We also note that our experiments were conducted in density gradients caused by changes in salinity; the effects of delayed settling across temperature-driven density gradients will be much less significant since at room temperature heat diffusivity in water is about two orders of magnitude larger than that of salt. Thus, the example from Alldredge et al. (2002) discussed previously would not have had as strong a potential for delayed settling behavior if aggregates were settling across a thermocline.

\subsection{Implications for biogeochemical cycling}

Understanding aggregate settling behavior, even on small scales, is important given the role of aggregates in biogeochemical cycles. Aggregates not only often dominate carbon export (Kiørboe, 2001), but also are typically colonized by highly active microbial communities (Smith et al., 1992; Grossart et al., 2007; Ziervogel and Arnosti 2008; Ziervogel et al., 2010). In the present study, observations of aggregates settling across sharp density gradients coupled with measurements of microbial enzyme activities provide insight into the manner in which delayed settling behavior may ultimately affect extent and location of organic matter remineralization in the water column. All enzymatic activities were one to two orders of magnitude higher on aggregates than in the surrounding tank water. These sinking 'packages' of organisms and enzymes can fuel remineralization of dissolved and particulate organic matter, including organic matter that may accumulate at density discontinuities, since the activities of extracellular 
enzymes initiate microbial remineralization of organic matter. Delayed settling behavior can therefore greatly enhance hydrolytic activity at the density interface. The calculations combining the observations of aggregate settling with the measured enzymatic activities demonstrate the manner in which stratification can increase the residence time of aggregates at a density interface, and thus the potential intensity of enzyme activities at depths with strong density gradients. These interactions could result in thin layers of dissolved organic matter, which have been observed in coastal waters (Chen et al. 2004).

A further effect is illustrated schematically in Fig. 8: the total extent as well as the distribution of enzyme activity changes under conditions of increasing stratification. As shown for Aggregate 10 from Experiment 2, aggregate 'residence time’ and thus the potential for enzyme activity in the region of a density interface increased by up to a factor of 18.4 in the highest level of stratification over the unstratified tank. Assuming that enzyme activities remain constant during sinking and taking $58 \mathrm{~cm}$ as the height of the water column in each tank, the fraction of total enzyme activity occurring in the region of the density interface increases from 33\% to 83\% between Tanks 1 and 3 (Fig. 8). Although aggregate settling occurs across much larger vertical scales in the ocean, increased stratification will likely have the same general effect of enhancing and redistributing microbial enzyme activity. Thus, high levels of microbial activities coupled with even modest decreases in settling velocity as aggregates pass through sharp density gradients in the surface ocean can lead to much higher total carbon remineralization - and nutrient regeneration - at shallower depths in the water column, potentially affecting $\mathrm{CO}_{2}$ uptake by the oceans and nutrient return to surface waters.

The fraction of particulate organic carbon exported from the euphotic zone is in general quite low, typically ranging from 5-25\%, but can vary significantly both temporally and spatially 
and is generally higher in coastal regions where there is a higher potential for delayed settling behavior (Buesseler, 1998; De La Rocha and Passow, 2007).

To determine how delayed settling behavior may affect the export of carbon, we can consider the journey of a single marine snow particle through the upper water column. Assuming a $100 \mathrm{~m}$ deep euphotic zone and a reasonable range of sinking speeds from 50-100 m day ${ }^{-1}$, a marine snow aggregate may take 1-2 days to settle out of the euphotic zone. However, the presence of a single sharp density gradient $\sim 2 \mathrm{~m}$ thick across which the aggregate displays delayed settling behavior can significantly increase this transport time. For example, if the aggregate decreases its settling velocity with a modest DSTS $=5$, total transport time through the euphotic zone could be increased by $10 \%$; with a more significant slow down, using DSTS = 100 , transport time could be increased by up to $200 \%$. Given that a longer transport time provides more opportunity for microbial remineralization of organic carbon, delayed settling behavior has the potential to substantially reduce carbon export. Moreover, although our experiments investigate delayed settling behavior of individual aggregates, a flux of many aggregates through a density gradient can result in accumulations of aggregates in thin layers, which has been previously proposed as a mechanism for aggregate thin layer formation (MacIntyre et al., 1995; Alldredge et al., 2002; Prairie et al., 2013). In these accumulations of aggregates in thin layers, microbial remineralization and zooplankton grazing can be further enhanced (Kiørboe, 2000; Menden-Deuer and Fredrickson, 2010).

The results of this study demonstrate that delayed settling behavior across sharp density gradients can be important for marine snow particles in the lab as well as for those in the field in certain coastal regions. Although this phenomenon is likely restricted to sharply stratified regions such as estuarine environments, delayed settling of marine snow can have profound effects for 
local carbon cycling given the important role of marine snow in the biological pump. Thus in strongly stratified coastal regions, particularly after an aggregate formation event such as at the end of a phytoplankton bloom (e.g. Riebesell, 1991), carbon export may be overestimated if small-scale aggregate settling behavior and vertical aggregate distributions are not considered. Further work coupling aggregate settling behavior and bacterial activity and studying delayed aggregate settling directly in the field will be important to understanding the importance of this phenomenon in the context of biogeochemical cycles in the natural environment. 


\section{Acknowledgements}

We would like to thank Shannon Smith, Avery Bullock, Adrienne Hoarfrost, Patrick McCarthy, Michelle Corea, Kathryn Valchar, Elaine Monbureau, and Amber Johnson for their help with experimental work and data processing. We would also like to thank Claudia Falcon, Shilpa Khatri, Sungduk Yu, and Chung-nan Tzou for their valuable feedback, in addition to two anonymous reviewers whose comments greatly improved the manuscript. This work is funded primarily by NSF CMG ARC-1025523. Additional funding came from NSF DMS-1009750, NSF RTG 0943851, NSF RAPID CBE, and NSF-OCE 1332881. 


\section{$\underline{\text { References }}$}

Abaid, N., Adalsteinsson, D., Agyapong, A., McLaughlin, R. M. 2004. An internal splash: levitation of falling spheres in stratified fluids. Physics of Fluids 16, 1567-1580.

Alldredge, A. L., Gotschalk, C. 1988. In situ settling behavior of marine snow. Limnol. Oceanogr. 33, 339-351.

Alldredge, A. L., Silver, M. W. 1988. Characteristics, dynamics, and significance of marine snow. Progress in Oceanography 20, 41-82.

Alldredge, A. L., Crocker, K. M. 1995. Why do sinking mucilage aggregates accumulate in the water column? The Science of the Total Environment 165, 15-22.

Alldredge, A. L., Cowles, T. J., MacIntyre, S., Rines, J. E. B., Donaghay, P. L., Greenlaw, C. F., Holliday, D. V., Dekshenieks, M. M., Sullivan, J. M., Zaneveld, J. R. V. 2002. Occurrence and mechanisms of formation of a dramatic thin layer of marine snow in a shallow Pacific fjord. Mar. Ecol. Prog. Ser. 233, 1-12.

Arnosti, C. 2011. Microbial extracellular enzymes and the marine carbon cycle. Ann. Review of Marine Science 3, 401-425. 
Batchelor, G. K. 1967. An introduction to fluid dynamics. Cambridge University Press, Cambridge, United Kingdom.

Buesseler, K. O. 1998. The decoupling of production and particulate export in the surface ocean. Global Biogeochemical Cycles 12, 297-310.

Camassa, R., Falcon, C., Lin, J., McLaughlin, R. M., Parker, R. 2009. Prolonged residence times for particles settling through stratified miscible fluids in the Stokes regime. Physics of Fluids 21, 031702.

Camassa, R., Falcon, C., Lin, J., McLaughlin, R. M., Mykins, N. 2010. A first-principle predictive theory for a sphere falling through sharply stratified fluid at low Reynolds number. J. Fluid Mech. 664, 436-465. doi:10.1017/S0022112010003800

Camassa, R., Khatri, S., McLaughlin, R. M., Prairie, J. C., White, B. L., Yu, S. 2013. Retention and entrainment effects: experiments and theory for porous spheres settling in sharply stratified fluids. Physics of Fluids 25, 081701.

Chen, R. F., Bissett, P., Coble, P. Conmy, R., Gardner, G. B., Moran, M. A., Wang, X., Wells, M. L., Whelan, P., Zepp, R. G. 2004. Chromophoric dissolved organic matter (CDOM) source characterization in the Louisiana Bight. Mar. Chem. 89, 257-272. 
De La Rocha, C. L., Passow, U. 2007. Factors influencing the sinking of POC and the efficiency of the biological carbon pump. Deep-Sea Res. II 54, 639-658.

Derenbach, J. B., Astheimer, H., Hansen, H. P., Leach, H. 1979. Vertical microscale distribution of phytoplankton in relation to the thermocline. Mar. Ecol. Prog. Ser. 1, 187-193.

Grossart, H-P, Tang, K. W., Kiørboe, T., Ploug, H. 2007. Comparison of cell-specific activity between free-living and attached bacteria using isolates and natural assemblages. FEMS Microbiol. Lett. 266, 194-200.

Guidi, L., Stemmann, L., Jackson, G. A., Ibanez, F., Claustre, H., Legendre, L., Picheral, M., Gorsky, G. 2009. Effects of phytoplankton community on production, size and export of large aggregates: A world-ocean analysis. Limnol. Oceanogr. 54, 1951-1963.

Hoppe, H-G. 1983. Significance of exoenzymatic activities in the ecology of brackish water: measurements by means of methylumbelliferyl-substrates. Mar. Ecol. Prog. Ser. 11, 299-308.

Jackson, G. A. 1994. Particle trajectories in a rotating cylinder: implications for aggregation incubations. Deep-Sea Res. I 41, 429-437.

Kilps, J. R., Logan, B. E., Alldredge, A. L. 1994. Fractal dimensions of marine snow determined from image analysis of in situ photographs. Deep-Sea Res. I 41, 1159-1169. 
Kindler, K., Khalili, A., Stocker, R. 2010. Diffusion-limited retention of porous particles at density interfaces. Proc. Natl. Acad. Sci. 107, 22163-22168.

Kiørboe, T. 2000. Colonization of marine snow aggregates by invertebrate zooplankton: abundance, scaling, and possible role. Limnol. Oceanogr. 45, 479-484.

Kiørboe, T. 2001. Formation and fate of marine snow: small-scale processes with large-scale implications. Scientia Marina 65, 57-71.

Lin, J. 2009. An experimental and mathematical study on the prolonged residence time of a sphere falling through stratified fluids at low Reynolds number. PhD thesis, University of North Carolina at Chapel Hill, NC.

Logan, B. E., Wilkinson, D. B. 1990. Fractal geometry of marine snow and other biological aggregates. Limnol. Oceanogr. 35, 130-136.

MacIntyre, S., Alldredge, A. L., Gotschalk, C. C. 1995. Accumulation of marine snow at density discontinuities in the water column. Limnol. Oceanogr. 40, 449-468.

McDonnell, A. M. P., Buesseler, K. O. 2010. Variability in the average sinking velocity of marine particles. Limnol. Oceanogr. 55, 2085-2096. 
McDougall, T. J., Barker, P. M. 2011. Getting started with TEOS-10 and the Gibbs Seawater (GSW) Oceanographic Toolbox SCOR/IAPSO WG127.

Menden-Deuer, S., Fredrickson, K. 2010. Structure-dependent, protistan grazing and its implication for the formation, maintenance and decline of phytoplankton patches. Mar. Ecol. Prog. Ser. 420, 57-71.

Ploug, H., Grossart, H-P, Azam, F., Jørgensen, B. B. 1999. Photosynthesis, respiration, and carbon turnover, in sinking marine snow from surface waters of Southern California Bight: implications for the carbon cycle in the ocean. Mar. Ecol. Prog. Ser. 179, 1-11.

Ploug, H., Iversen, M. H., Fischer, G. 2008. Ballast, sinking velocity, and apparent diffusivity within marine snow and zooplankton fecal pellets: implications for substrate turnover by attached bacteria. Limnol. Oceanogr. 53, 1878-1886.

Prairie, J. C., Ziervogel, K., Arnosti, C., Camassa, R., Falcon, C., Khatri, S., McLaughlin, R. M., White, B. L., Yu, S. 2013. Delayed settling of marine snow at sharp density transitions driven by fluid entrainment and diffusion-limited retention. Mar. Ecol. Progr. Ser. 487, 185-200.

Riebesell, U. 1991. Particle aggregation during a diatom bloom. II. Biological aspects. Mar. Ecol. Progr. Ser. 69, 281-291. 
Shanks, A. L., Edmondson, E. W. 1989. Laboratory-made artificial marine snow: A biological model of the real thing. Mar. Biol. 101, 463-470.

Shanks, A. L. 2002. The abundance, vertical flux, and still-water and apparent sinking rates of marine snow in a shallow coastal water column. Cont. Shelf Res. 22, 2045-2064.

Smith, D. C., Simon, M., Alldredge, A.L., Azam, F. 1992. Intense hydrolytic enzyme activity on marine aggregates and implications for rapid particle dissolution. Nature 359, 139-142.

Srdić-Mitrović, A. N., Mohamed, N. A., Fernando, H. J. S. 1999 Gravitational settling of particles through density interfaces. J. Fluid Mech. 381, 175-198.

Turner, J. T. 2002. Zooplankton fecal pellets, marine snow and sinking phytoplankton blooms. Aquat. Microb. Ecol. 27, 57-102.

White, F. M. 1974. Viscous fluid flow. McGraw-Hill, New York, United States.

Ziervogel, K., Forster, S. 2005. Aggregation and sinking behaviour of resuspended fluffy layer material. Cont. Shelf Res. 25, 1853-1863.

Ziervogel, K., Arnosti, C. 2008. Polysaccharide hydrolysis in aggregates and free enzyme activity in aggregate-free seawater from the north-eastern Gulf of Mexico. Environmental Microbiology 10, 289-299. 
Ziervogel, K., Steen, A. D., Arnosti, C. 2010. Changes in the spectrum and rates of extracellular enzyme activities in seawater following aggregate formation. Biogeosciences 7, 1007-1015. 
Table 1. Description of the three aggregate settling experiments, showing the density $(\rho)$ of the source water used to form the aggregates, the density of the top layer, the density of the bottom layer in each of the three tanks, the average porosity $(P)$ of the aggregates, and the number of aggregates observed in the each of the experiments (in all three tanks). For each density value, the salinity in (psu) is given in parentheses.

\begin{tabular}{|c|c|c|c|c|c|c|c|}
\hline \multirow{2}{*}{$\begin{array}{c}\text { Exp. } \\
\text { Number }\end{array}$} & \multirow{2}{*}{$\begin{array}{l}\text { Source } \\
\text { water } \rho \\
\left(\mathrm{g} \mathrm{cm}^{-3}\right)\end{array}$} & \multirow{2}{*}{$\begin{array}{c}\text { Top layer } \rho \\
\text { (all tanks) } \\
\left(\mathrm{g} \mathrm{cm}^{-3}\right)\end{array}$} & \multicolumn{3}{|c|}{ Bottom layer $\rho\left(\mathrm{g} \mathrm{cm}^{-3}\right)$} & \multirow{2}{*}{$\begin{array}{c}\text { Avg. } P \text { of } \\
\text { aggregates } \\
( \pm \text { SD })\end{array}$} & \multirow{2}{*}{$\begin{array}{c}\text { Total no. of } \\
\text { aggregates } \\
\text { observed }\end{array}$} \\
\hline & & & Tank 1 & Tank 2 & Tank 3 & & \\
\hline 1 & $\begin{array}{l}1.0225 \\
(32.2)\end{array}$ & $\begin{array}{l}1.0225 \\
(32.2)\end{array}$ & $\begin{array}{l}1.0274 \\
(38.6)\end{array}$ & $\begin{array}{l}1.0322 \\
(44.9)\end{array}$ & $\begin{array}{l}1.0372 \\
(51.4)\end{array}$ & $\begin{array}{l}0.995 \pm \\
0.001\end{array}$ & 8 \\
\hline 2 & $\begin{array}{l}1.0225 \\
(32.3)\end{array}$ & $\begin{array}{l}1.0225 \\
(32.5)\end{array}$ & $\begin{array}{l}1.0271 \\
(38.6)\end{array}$ & $\begin{array}{l}1.0323 \\
(45.3)\end{array}$ & $\begin{array}{l}1.0373 \\
(51.8)\end{array}$ & $\begin{array}{l}0.998 \pm \\
0.006\end{array}$ & 10 \\
\hline 3 & $\begin{array}{l}1.0250 \\
(35.6)\end{array}$ & $\begin{array}{l}1.0249 \\
(35.2)\end{array}$ & $\begin{array}{l}1.0295 \\
(41.3)\end{array}$ & $\begin{array}{l}1.0345 \\
(47.8)\end{array}$ & $\begin{array}{l}1.0393 \\
(54.0)\end{array}$ & $\begin{array}{l}0.986 \pm \\
0.005\end{array}$ & 9 \\
\hline
\end{tabular}


Table 2. Equivalent spherical diameter (ESD) and aggregate density for each aggregate from the three aggregate settling experiments, along with normalized excess aggregate density, $\overline{\Delta \rho}$, for each of the three tanks.

\begin{tabular}{|c|c|c|c|c|c|c|}
\hline $\begin{array}{c}\text { Exp. } \\
\text { Number }\end{array}$ & $\begin{array}{c}\text { Aggregate } \\
\text { Number }\end{array}$ & $\begin{array}{c}\text { Aggregate } \\
\text { ESD }(\mathrm{cm})\end{array}$ & $\begin{array}{c}\text { Aggregate } \\
\text { Density } \\
\left(\mathrm{g} \mathrm{cm}^{-3}\right)\end{array}$ & $\overline{\Delta \rho}$ in Tank 1 & $\overline{\Delta \rho}$ in Tank 2 & $\overline{\Delta \rho}$ in Tank 3 \\
\hline \multirow{6}{*}{1} & 1 & 0.190 & 1.0279 & 1.10 & 0.56 & 0.37 \\
\cline { 2 - 7 } & 2 & 0.289 & 1.0276 & 1.04 & 0.53 & 0.35 \\
\cline { 2 - 7 } & 3 & 0.249 & 1.0272 & 0.96 & 0.48 & 0.32 \\
\cline { 2 - 7 } & 4 & 0.282 & 1.0241 & 0.33 & 0.16 & 0.11 \\
\cline { 2 - 7 } & 5 & 0.222 & 1.0245 & 0.41 & 0.21 & 0.14 \\
\cline { 2 - 7 } & 6 & 0.225 & 1.0251 & 0.53 & 0.27 & 0.18 \\
\cline { 2 - 7 } & 7 & 0.233 & 1.0243 & 0.37 & 0.19 & 0.12 \\
\hline \multirow{6}{*}{2} & 8 & 0.257 & 1.0257 & 0.65 & 0.33 & 0.22 \\
\cline { 2 - 7 } & 1 & 0.258 & 1.0290 & 1.41 & 0.66 & 0.44 \\
\cline { 2 - 7 } & 2 & 0.269 & 1.0265 & 0.87 & 0.41 & 0.27 \\
\cline { 2 - 7 } & 3 & 0.283 & 1.0286 & 1.33 & 0.62 & 0.41 \\
\cline { 2 - 7 } & 4 & 0.300 & 1.0263 & 0.83 & 0.39 & 0.26 \\
\cline { 2 - 7 } & 5 & 0.249 & 1.0260 & 0.76 & 0.36 & 0.24 \\
\cline { 2 - 7 } & 7 & 0.203 & 1.0347 & 2.65 & 1.24 & 0.82 \\
\cline { 2 - 7 } & 8 & 0.221 & 1.0276 & 1.11 & 0.52 & 0.34 \\
\cline { 2 - 7 } & 9 & 0.267 & 1.0267 & 0.91 & 0.43 & 0.28 \\
\hline \multirow{3}{*}{3} & 10 & 0.176 & 1.0295 & 1.52 & 0.71 & 0.47 \\
\cline { 2 - 7 } & 1 & 0.262 & 1.0280 & 1.20 & 0.56 & 0.37 \\
\cline { 2 - 7 } & 2 & 0.102 & 1.0540 & 6.33 & 3.03 & 2.02 \\
\cline { 2 - 7 } & 3 & 0.096 & 1.0432 & 3.98 & 1.91 & 1.27 \\
\cline { 2 - 7 } & 4 & 0.093 & 1.0524 & 5.98 & 2.86 & 1.91 \\
\cline { 2 - 7 } & 5 & 0.107 & 1.0462 & 4.63 & 2.22 & 1.48 \\
\cline { 2 - 7 } & 6 & 0.104 & 1.0465 & 4.70 & 2.25 & 1.50 \\
\cline { 2 - 7 } & 7 & 0.115 & 1.0413 & 3.57 & 1.71 & 1.14 \\
\cline { 2 - 7 } & 8 & 0.115 & 1.0402 & 3.33 & 1.59 & 1.06 \\
\hline
\end{tabular}


Table 3. Density profile properties for each tank and experiment are given, including the fit parameters mid-depth, $z_{0}$ (cm below surface), and density transition thickness, $z_{t h}(\mathrm{~cm})$, in addition to the maximum buoyancy frequency, $N\left(\mathrm{~s}^{-1}\right)$, as calculated from the density profiles.

\begin{tabular}{|l|l|l|l|l|}
\hline \multicolumn{2}{|c|}{} & Tank 1 & Tank 2 & Tank 3 \\
\hline \multirow{3}{*}{ Exp. 1 } & $z_{0}(\mathrm{~cm})$ & 37.1 & 37.5 & 36.8 \\
\cline { 2 - 5 } & $Z_{\text {th }}(\mathrm{cm})$ & 1.95 & 1.44 & 1.01 \\
\cline { 2 - 5 } & $\max . N\left(\mathrm{~s}^{-1}\right)$, & 1.10 & 1.79 & 2.63 \\
\hline \multirow{5}{*}{ Exp. 2 } & $z_{0}$ & 35.1 & 35.4 & 36.0 \\
\cline { 2 - 5 } & $Z_{\text {th }}(\mathrm{cm})$ & 0.93 & 0.93 & 0.95 \\
\cline { 2 - 5 } & $\max . N\left(\mathrm{~s}^{-1}\right)$, & 1.54 & 2.24 & 2.72 \\
\hline \multirow{3}{*}{ Exp. 3 } & $z_{0}(\mathrm{~cm})$ & 33.6 & 34.0 & 35.1 \\
\cline { 2 - 5 } & $Z_{\text {th }}(\mathrm{cm})$ & 0.96 & 0.82 & 0.94 \\
\cline { 2 - 5 } & $\max . N\left(\mathrm{~s}^{-1}\right)$, & 1.51 & 2.36 & 2.70 \\
\hline
\end{tabular}


Table 4. Delayed settling time scale (DSTS) and normalized minimum settling velocity (NMSV) for each aggregate from the three aggregate settling experiments in each of the three tanks.

\begin{tabular}{|c|c|c|c|c|c|c|c|}
\hline $\begin{array}{c}\text { Exp. } \\
\text { Number }\end{array}$ & $\begin{array}{c}\text { Aggregate } \\
\text { Number }\end{array}$ & $\begin{array}{c}\text { NMSV in } \\
\text { Tank 1 }\end{array}$ & $\begin{array}{c}\text { NMSV in } \\
\text { Tank 2 }\end{array}$ & $\begin{array}{c}\text { NMSV in } \\
\text { Tank 3 }\end{array}$ & $\begin{array}{c}\text { DSTS in } \\
\text { Tank 1 }\end{array}$ & $\begin{array}{c}\text { DSTS in } \\
\text { Tank 2 }\end{array}$ & $\begin{array}{c}\text { DSTS in } \\
\text { Tank 3 }\end{array}$ \\
\hline \multirow{6}{*}{1} & 1 & 0.06 & 0 & 0 & 28.6 & 40.4 & 114.6 \\
\cline { 2 - 8 } & 2 & 0.02 & 0.02 & -0.01 & 48.6 & 129.2 & 220.7 \\
\cline { 2 - 8 } & 3 & 0.03 & -0.05 & -0.01 & 35.3 & 95.0 & 160.4 \\
\cline { 2 - 8 } & 4 & 0 & 0 & -0.02 & 60.5 & 121.2 & 219.9 \\
\cline { 2 - 8 } & 5 & 0 & -0.01 & 0 & 42.6 & 80.8 & 165.4 \\
\cline { 2 - 8 } & 6 & 0 & -0.01 & -0.03 & 52.9 & 87.1 & 222.1 \\
\cline { 2 - 8 } & 7 & 0.02 & -0.01 & -0.01 & 42.8 & 90.1 & 152.6 \\
\hline \multirow{6}{*}{2} & 8 & 0.07 & 0.05 & 0.01 & 29.0 & 45.3 & 133.8 \\
\cline { 2 - 8 } & 1 & 0.58 & 0.18 & 0.04 & 7.4 & 31.0 & 78.6 \\
\cline { 2 - 8 } & 2 & 0.36 & 0.24 & 0.09 & 16.3 & 28.2 & 45.7 \\
\cline { 2 - 8 } & 3 & 0.55 & 0.13 & 0.06 & 11.1 & 43.5 & 48.0 \\
\cline { 2 - 8 } & 4 & 0.11 & 0 & -0.01 & 40.0 & 164.0 & 267.5 \\
\cline { 2 - 8 } & 5 & 0.03 & -0.02 & -0.01 & 45.3 & 131.5 & 185.8 \\
\cline { 2 - 8 } & 6 & 0.72 & 0.62 & 0.57 & 4.4 & 8.6 & 12.6 \\
\cline { 2 - 8 } & 7 & 0.41 & 0.02 & 0 & 15.1 & 52.2 & 62.4 \\
\cline { 2 - 8 } & 8 & 0.06 & 0 & -0.01 & 51.3 & 160.1 & 271.7 \\
\cline { 2 - 8 } & 9 & 0.53 & 0.11 & 0.03 & 11.0 & 36.7 & 53.3 \\
\hline 3 & 10 & 0.41 & 0 & -0.01 & 18.2 & 81.8 & 157.9 \\
\hline & 1 & 0.53 & 0.31 & 0.16 & 5.5 & 15.0 & 20.8 \\
\cline { 2 - 8 } & 2 & 0.42 & 0.22 & 0.17 & 7.6 & 21.6 & 22.1 \\
\cline { 2 - 8 } & 3 & 0.50 & 0.25 & 0.11 & 7.3 & 20.5 & 21.7 \\
\cline { 2 - 8 } & 4 & 0.59 & 0.26 & 0.19 & 4.7 & 15.6 & 18.7 \\
\cline { 2 - 8 } & 5 & 0.54 & 0.24 & 0.25 & 6.8 & 19.3 & 18.7 \\
\cline { 2 - 8 } & 6 & 0.65 & 0.22 & 0.24 & 4.4 & 19.6 & 20.5 \\
\cline { 2 - 8 } & 7 & 0.58 & 0.35 & 0.25 & 5.2 & 13.3 & 15.5 \\
\cline { 2 - 8 } & 8 & 0.43 & 0.19 & 0.18 & 9.2 & 21.3 & 22.9 \\
\hline
\end{tabular}


Table 5. Average bacterial enzymatic activities measured in aggregates (AGG; pmol mL ${ }^{-1} \mathrm{hr}^{-1}$ ) and in the surrounding tank water (SW; pmol mL ${ }^{-1} \mathrm{hr}^{-1}$ ) for each experiment (shown with \pm standard deviation). Exp. 1 and 3 had $n=5$ aggregates in $n=3$ vials per substrate. Exp. 2 had $n=$ 3 aggregates in $n=2$ vials per substrate (see text for details).

\begin{tabular}{|l|l|l|l|l|l|l|}
\hline \multirow{2}{*}{$\begin{array}{l}\text { Exp. } \\
\text { Number }\end{array}$} & \multicolumn{2}{|l|}{ Peptidase } & \multicolumn{2}{l|}{$\beta$-Glucosidase } & \multicolumn{2}{l|}{$\alpha$-Glucosidase } \\
\cline { 2 - 7 } & AGG & SW & AGG & SW & AGG & SW \\
\hline 1 & $\begin{array}{l}9031 \pm \\
2082\end{array}$ & $\begin{array}{l}122 \pm \\
4\end{array}$ & $\begin{array}{l}475 \pm \\
107\end{array}$ & $\begin{array}{l}3.1 \pm \\
0^{*}\end{array}$ & $109 \pm 14$ & $1.7 \pm 0^{*}$ \\
\hline 2 & $\begin{array}{l}12320 \pm \\
10\end{array}$ & $107 \pm$ & $260 \pm$ & $3 \pm 0^{*}$ & $115 \pm 5$ & $2 \pm 0^{*}$ \\
\hline 3 & $\begin{array}{l}11870 \pm \\
625\end{array}$ & $56 \pm 2$ & $74 \pm 21$ & $1 \pm 0^{*}$ & $96 \pm 23$ & $1 \pm 0^{*}$ \\
\hline
\end{tabular}

$* \leq 0.2$ 


\section{$\underline{\text { Figures }}$}

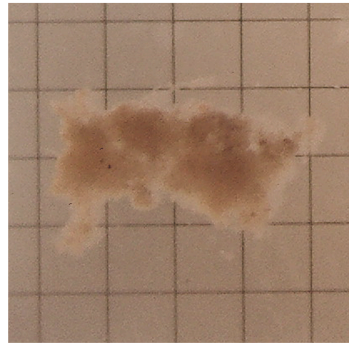

Aggregate 3

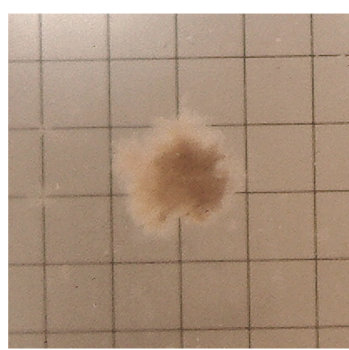

Aggregate 9

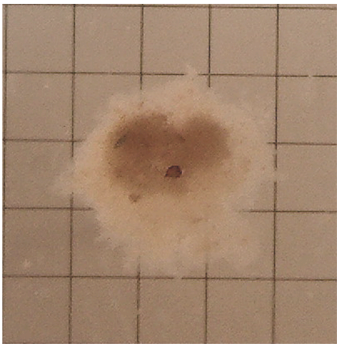

Aggregate 4

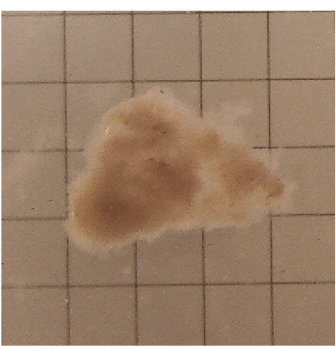

Aggregate 10

Figure 1. Photographs of example aggregates from Experiment 2 showing variation in aggregate size, shape, and appearance. 


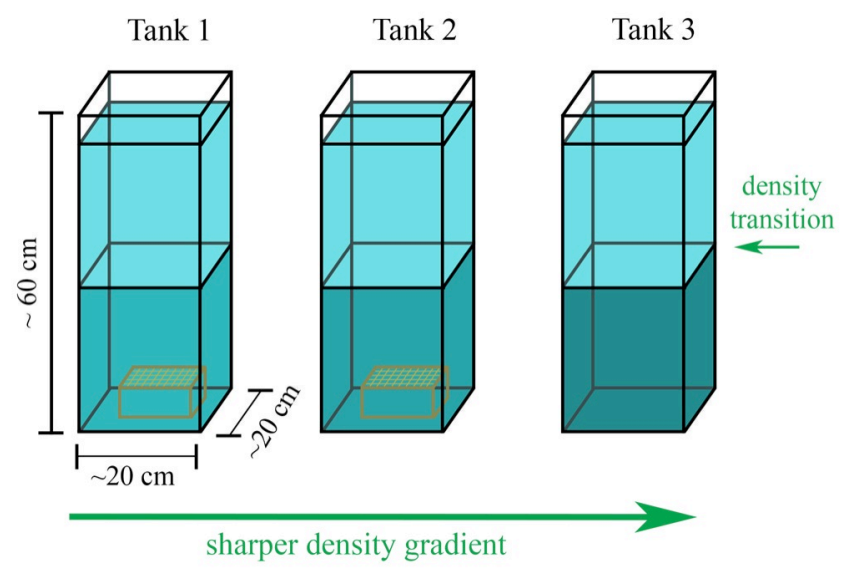

Figure 2. Schematic showing experimental setup of aggregate settling experiments. Aggregates are observed as they settled through 3 stratified tanks with increasingly sharp density gradients. At the base of Tanks 1 and 2, square grid containers were used to individually retrieve sinking aggregates (see text.) 

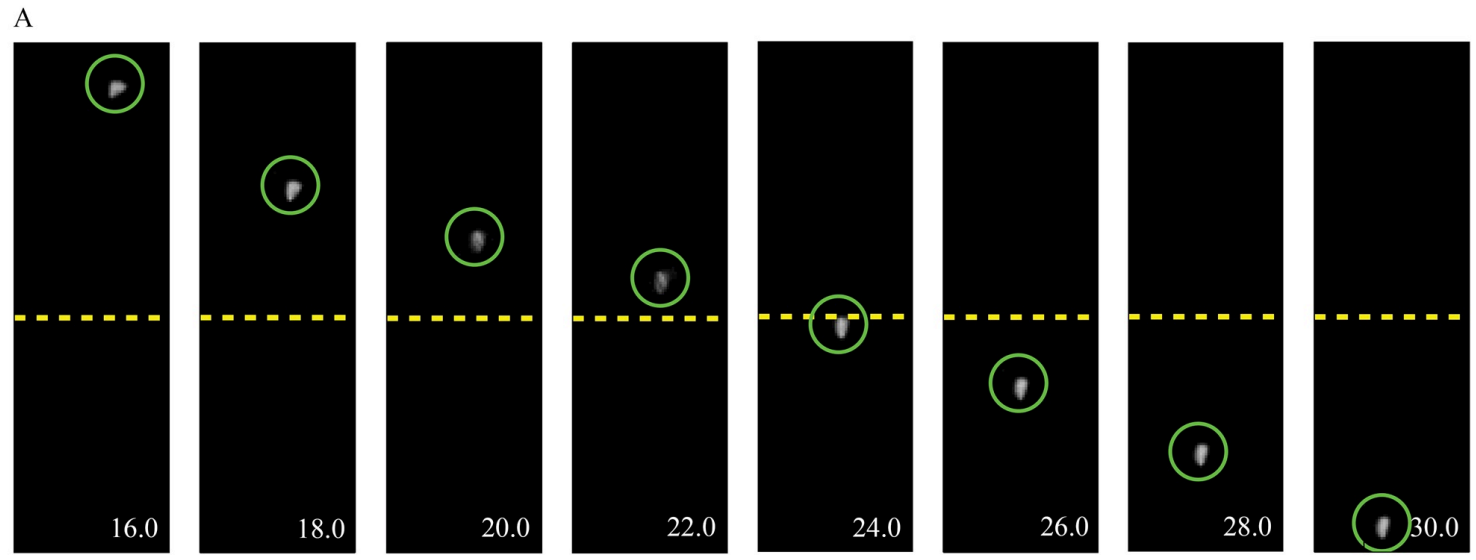

B
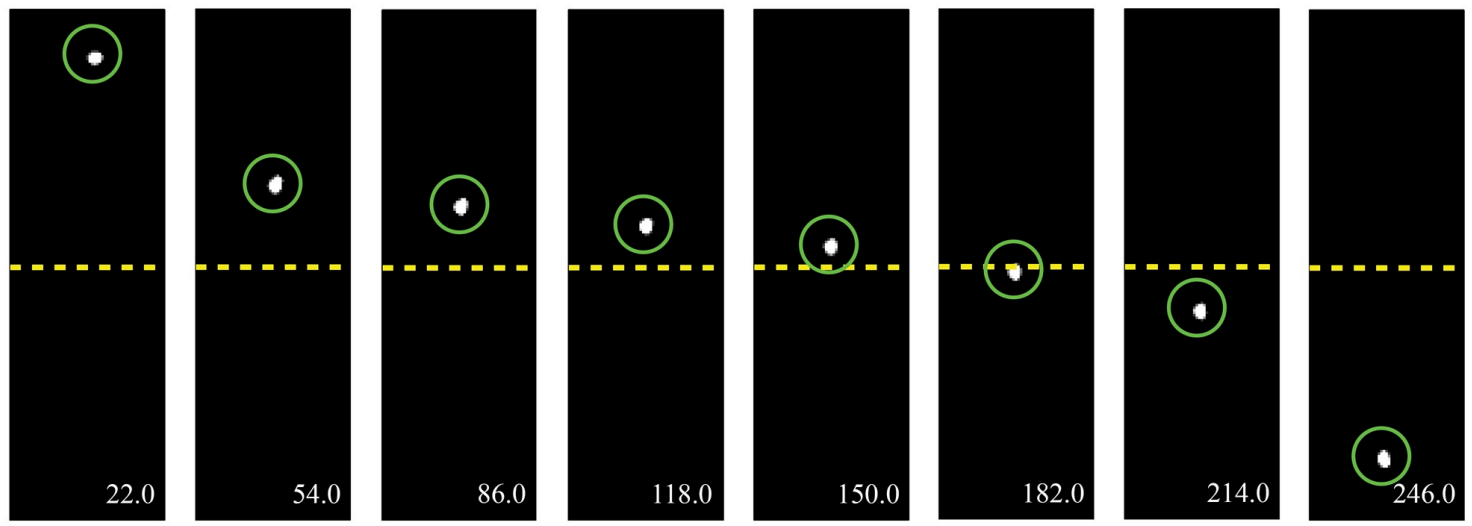

Figure 3. Sequential panels show a subsection of images of (A) Aggregate 10 settling in Tank 1 of Experiment 2 and (B) the same aggregate settling in Tank 3 of Experiment 2. Location of density gradient is shown as dashed line. Time stamps are shown in seconds in the bottom right corner of images. 

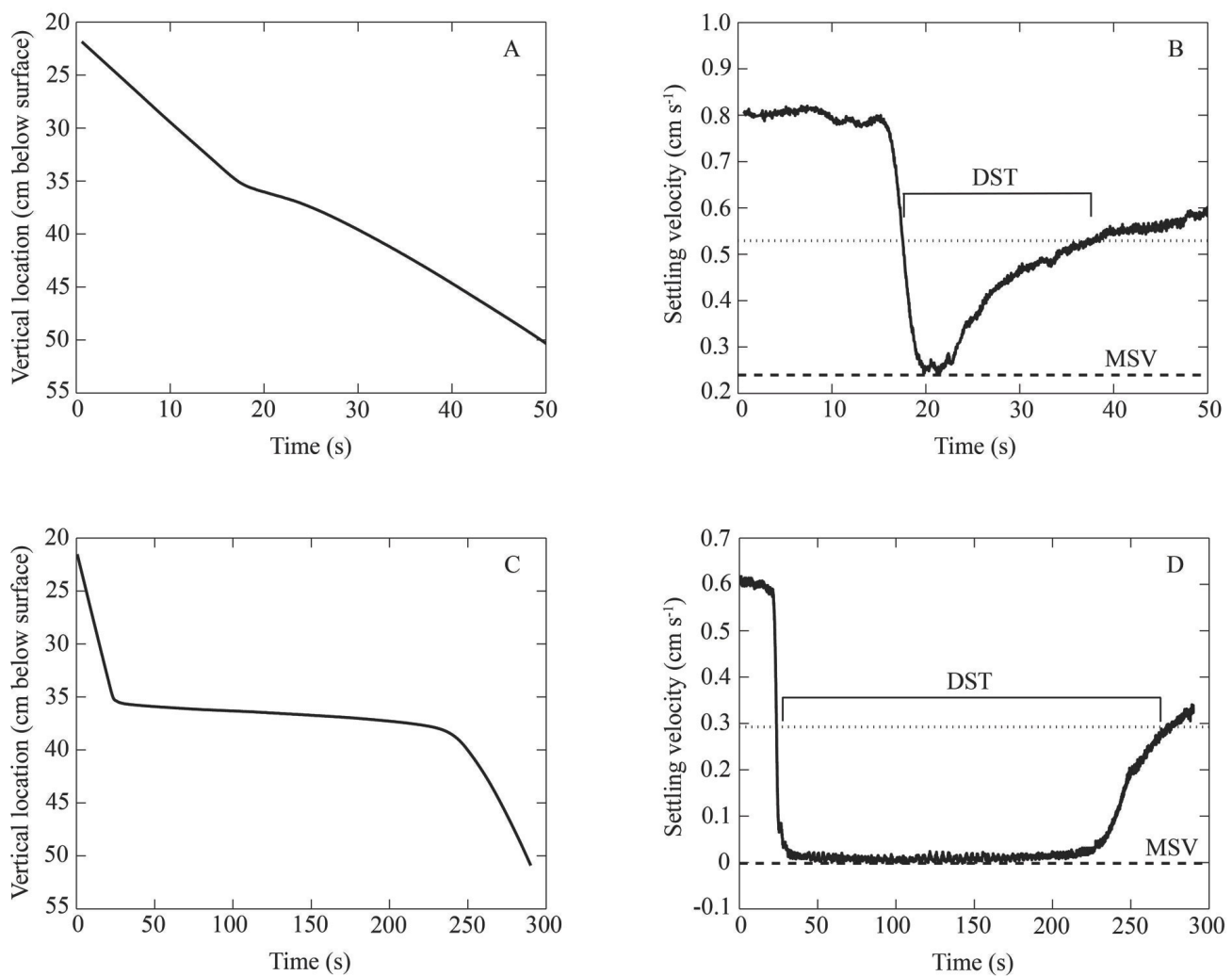

Figure 4. Example of aggregate settling behavior through density transition. (A) Aggregate vertical location over time for Aggregate 10 from Experiment 2 in Tank 1 (weakest density gradient). (B) Smoothed aggregate settling velocity over time for the profile in (A). (C) Aggregate vertical location over time for same aggregate in Tank 3 (sharpest density gradient). (D) Smoothed aggregate settling velocity over time for the profile in (C). In plots (B) and (D), the dashed line shows the minimum settling velocity (MSV, not normalized) and the dotted line represents $90 \%$ of the terminal velocity in the bottom layer, which was used to find delayed settling time (DST, shown with brackets). 

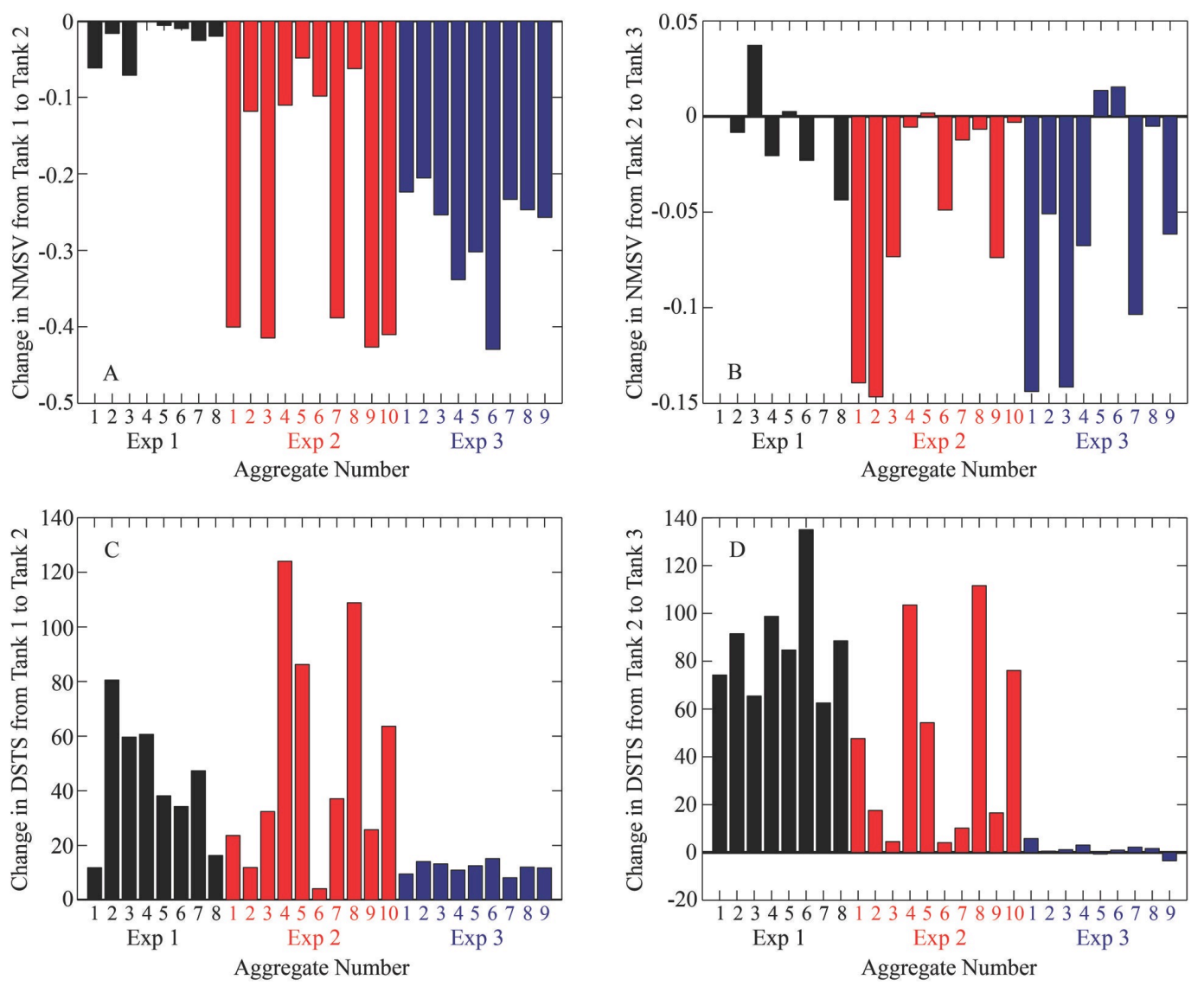

Figure 5. (A) Change in NMSV from Tank 1 to Tank 2 for each aggregate in the three experiments. (B) Change in NMSV from Tank 2 to Tank 3. (C) Change in DSTS from Tank 1 to Tank 2 for each aggregate in the three experiments. (D) Change in DSTS from Tank 2 to Tank 3. In all panels, different colors represent the three different experiments. 

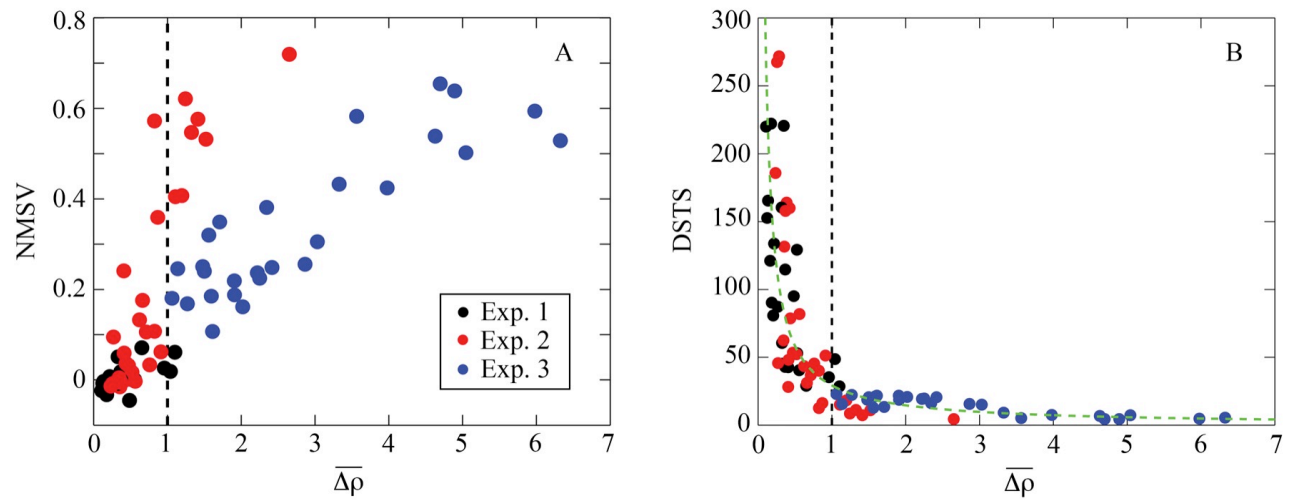

Figure 6. (A) Plot of normalized minimum settling velocity (NMSV) vs. aggregate normalized excess density, $\overline{\Delta \rho}$, for each of the aggregates in all three settling experiments. (B) Delayed settling time scale (DSTS) vs. $\overline{\Delta \rho}$. Green dashed line shows power-law fit with slope of -1 $\left(\mathrm{r}^{2}=0.56\right)$. Vertical dashed black line represents $\overline{\Delta \rho}=1$ in both (A) and (B). 

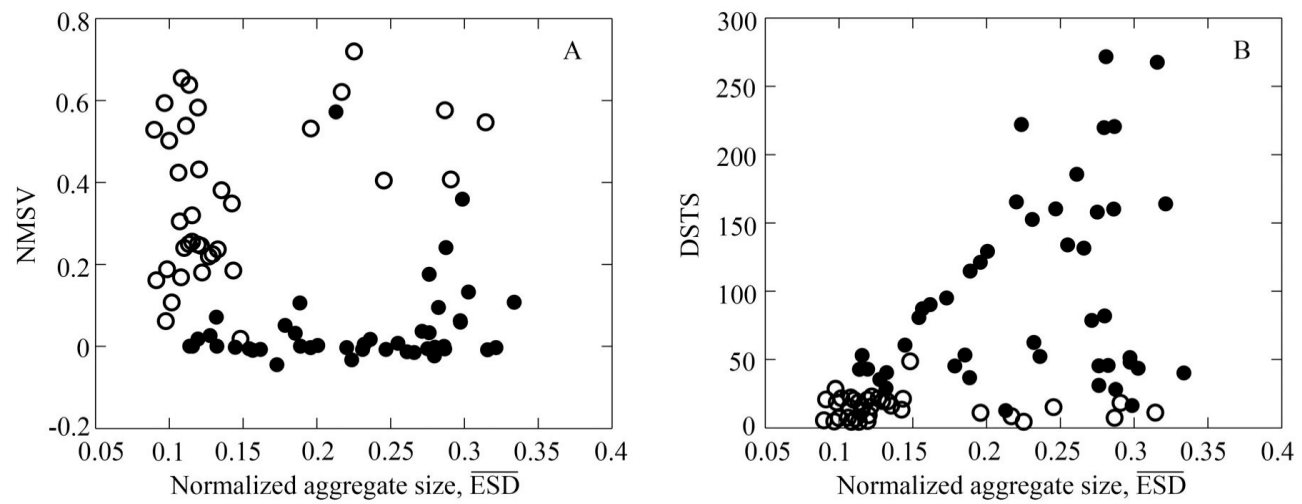

Figure 7. (A) Plot of normalized minimum settling velocity (NMSV) vs. normalized aggregate size, $\overline{\mathrm{ESD}}$, for each of the aggregates in all three settling experiments. (B) Delayed settling time scale (DSTS) vs. $\overline{\text { ESD }}$. For both plots, aggregates with $\overline{\Delta \rho}<1$ are shown as open circles and aggregates with $\overline{\Delta \rho}>1$ are shown as solid circles. 


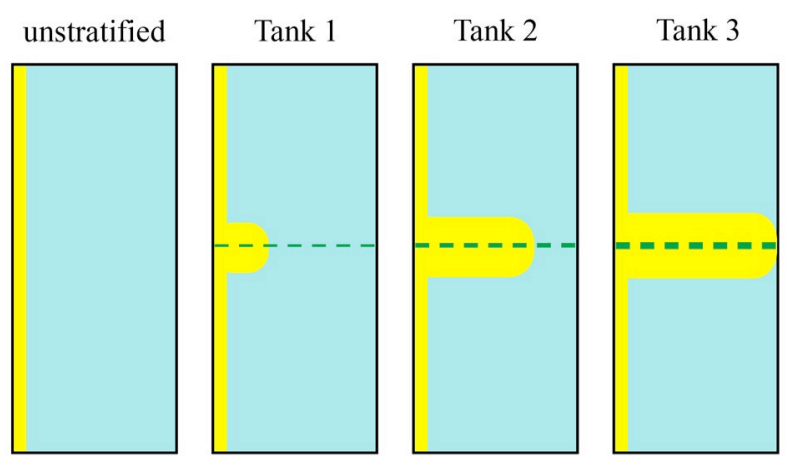

Figure 8. Schematic showing the increase in microbial enzyme activity (shown in yellow) at the density interface, as well as an overall increase in enzyme activities in the tanks with increasingly sharp stratification (illustrated by the thickness of the dashed line). 